\title{
POSTERIOR PHARYNGEAL WALL AUGMENTATION WITH MUSCULAR FLAP VERSUS MUSCULOMUCOSAL FLAP FOR CORRECTION OF VELOPHARYNGEAL INCOMPETENCE
}

\author{
Mahmoud E.Khalifa*, Mohamed K. Allam* and Mohamed E. Darwish ${ }^{* *}$
}

\begin{abstract}
This study was aimed to evaluate and compare the posterior pharyngeal wall augmentation using muscular flap versus musculomucosal flap for correction of velopharyngeal incompetence (VPI).

Patients and methods: this study was conducted on twenty children (13 males and 7 females) complaining from VPI with age ranging between 6.5 and 13 years with a mean of age 8.7 years. All patients were treated surgically using posterior pharyngeal wall augmentation. Patients were classified into two equal groups according to the type of flap technique used for posterior pharyngeal wall augmentation. Group I included 10 patients ( 7 males and 3 females) were treated by muscular flap. Group II included 10 patients ( 6 males and 4 females) were treated by musculomucosal flap. The preoperative and postoperative assessments for patients with VPI included clinical examination of the voice, nasopharyngoscopy and computed tomography (CT) scans.
\end{abstract}

Results: Regarding clinical presentation (hypernasality and nasal regurgitation of fluid), all patients in both groups had no nasal regurgitation of fluid or food which represents $100 \%$. As regard the overall nasalance results (Nasal sentence) measured by nasometry in both groups there was noticeable improvement. But when comparing overall nasalance results between both groups there was no significant difference .Competence and borderline closure was achieved in $65 \%$ for patients of both groups. The VP gap size reduction was achieved in both groups, however there was no significant difference regarding reduction of median VP gap size.

Conclusion: At the end, as there no significant difference in the results of both groups: the myomucosal flap technique for posterior pharyngeal wall augmentation is simple and easier than the muscular flap technique and the posterior pharyngeal wall augmentation is a good technique for treatment of VPI

KEY WORDS: VPI, Posterior pharyngeal wall augmentation, nasometer.

* Assistant professor of Oral and Maxillofacial Surgery, Faculty of Dentistry, Tanta University

** Lecturer of Oral and Maxillofacial Surgery, Faculty of Dentistry, Tanta University

*** Lecturer of Otorhinolaryngology Department, Faculty of Medicine, Tanta University 


\section{INTRODUCTION}

Normal velopharyngeal (VP) closure involves the actions of many muscles, including the levator veli palatini (LVP), palatopharyngeus, and superior constrictor, the varying contributions of these muscles to velar closure in normal individuals result in a variety of normal closure patterns, including coronal, sagittal, and circular. ${ }^{1}$

Normal velopharyngeal closure patterns vary in the population, half of the population will demonstrate a coronal pattern, with the free edge of the soft palate approximating the posterior pharyngeal wall. The circular pattern of closure was exhibited by $40 \%$ of people, with lateral pharyngeal walls and soft palate contributing to closure. The sagittal closure pattern is found in $15 \%$ of the population, with the soft palate contributes little to the closure of the velopharyngeal sphincter whereas the lateral walls medialize to create an airtight seal. ${ }^{2}$

Velopharyngeal insufficiency (VPI) is defined anatomically as the inability to completely close the VP port during production of sounds that require velar closure. As a result, hypernasal resonance, nasal air emissions, and compensatory misarticulations (among others) lead to speech intelligibility problems ${ }^{3}$. After overt cleft palate repair, VPI speech has been reported in as many as $75 \%$ of patients ${ }^{4}$. Other causes for VPI include submucous cleft palate, neuromuscular disorders, syndromes, or no apparent etiology. ${ }^{5}$

Passavant $(\mathbf{1 8 6 5})^{6}$ reported surgical adhesion of the posterior border of the soft palate to the posterior pharyngeal wall, which can be considered the predecessor of attachment of a formal posterior pharyngeal flap to the soft palate. Since that time the use of removable devices designed correct the VPI, also a number of surgical procedures have been devised to restore the physiologic closure of this sphincter-like mechanism. ${ }^{7}$

The goals of surgery are to eliminate the symptoms of hypernasality and eliminate audible nasal emissions without causing complete obstruction of the velopharyngeal port, allowing for nasal breathing and nasal resonance. ${ }^{8}$

Multiple procedures have been described, The first option category consists of (1) lengthening the palate by retropositioning the velum, which can be achieved with a V-Y pushback procedure, an intravelar veloplasty, ${ }^{9}$ or a double-opposing Z-plasty; ${ }^{10}$ and (2) palatal re-repair. ${ }^{11}$

The second option category involves reduction of the static opening between the nasal and oral pharynges ${ }^{12-14}$ which is considered a velopharyngeal narrowing procedure. This narrowing may be accomplished with a pharyngeal flap or with posterior pharyngeal wall augmentation (either with rolled pharyngeal flap or synthetic implant) or with sphincter pharyngoplasty. The pharyngeal flap creates a single subtotal central obstruction of the velopharyngeal port, leaving 2 open ports laterally. Sphincter pharyngoplasty diminishes the crosssectional area of the central port.

The treatment for refractory VPI can be surgical: revision palatoplasty, posterior pharyngeal flap (PPF), or dynamic sphincter pharyngoplasty (DSP) are the standard options ${ }^{14}$, though some centers have used prosthetic obturators. ${ }^{16}$ Secondary speech surgeries, however, are not without risk. Of greatest clinical consequence is the potential for the iatrogenic induction of obstructive sleep apnea (OSA) in high-risk patients. ${ }^{17}$ This adverse consequence is even more germane to cases requiring velopharyngoplasty revision: when VPI persists despite secondary speech surgery, the standard approach has been to repeat the operation in a more aggressive fashion (i.e., create a larger posterior pharyngeal flap or a tighter sphincter pharyngoplasty. ${ }^{18}$ Posterior pharyngeal augmentation could represent an alternative and/or adjunct to traditional speech surgery. ${ }^{19}$

The aim of this work was to compare results of augmentation pharyngoplasty using 
musculomucosal flap versus Muscular flap in the treatment of velopharyngeal insufficiency after cleft palate repair.

\section{PATIENTS AND METHODS}

A random group of twenty patients with VPI after cleft palate repair was studied in the Oral and Maxillofacial surgery department, Faculty of Dentistry. Tanta University. Full history was obtained from each patient with physical examination stressing on absence of fistula, hypernasality, nasal emission or regurgitation, compensatory misarticulation and facial grimacing.

\section{Preoperative and Post operative evaluation}

The assessments for patients with VPI include clinical examination of the voice, nasopharyngoscopy and computed tomography (CT) scans according to the protocol of nasality evaluation ( perceptual evaluation of the voice and Nasopharyngoscopy) in Phoniatrics unit, Faculty of Medicine, Tanta University.

\section{A) The perceptual evaluation of the voice:}

(Judged by a speech therapist)

- All the patients were evaluated preoperative, one, 6 and 9 months after the surgery.

1- The hypernasality degree was evaluated subjectively with the Borel-Maisonny ${ }^{20}$ score, based on the audible nasal emission, intelligibility and compensatory articulation during phonation and theses elemens were graded along a 5-point scale starting with 0 (normal) to 4 (severely affected).

2- Objective and quantitative assessment of nasalance was obtained by using a Nasometer ${ }^{21,22}$ (Figure 1)

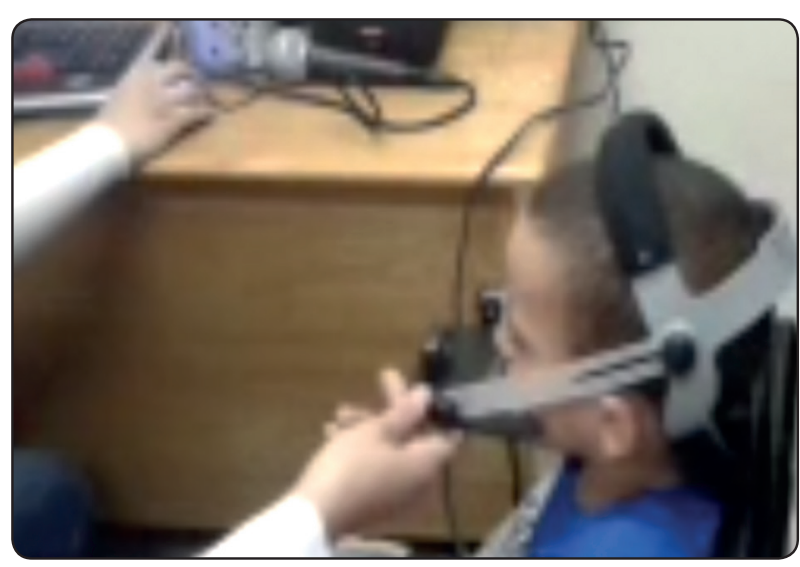

Fig. (1) Quantitative assessment of nasalance using Nasometer

\section{B) The Nasopharyngoscopy**}

- All the patients were evaluated preoperative, one and 9 months after the surgery.

- The nasopharyngoscopy was performed under local anesthesia for direct visualization of the velopharyngeal sphincter during speech. ${ }^{23,24}$

- The main parameters of analysis were the adequacy of velopharyngeal closure in addition to the type of closure (coronal, sagittal, or circular) was noted.

- Velopharyngeal closure was evaluated and classified according to criteria recommended by the international working group that reported a standardized grading scale for reporting finding on nasopharyngoscopy The overall velopharyngeal gap size was classified as large (VP closure less than $50 \%$ ), moderate (closure between 50 and $80 \%$ ), or small (closure greater than $80 \%)$. $^{25}$

\section{C) Computed tomography (CT) scans:}

- All the patients were evaluated Preoperative, immediately and 9 months after the surgery.

\footnotetext{
* Nasometery (Kay Elemetrics, model 6200. Corp. Lincoln Park. N.J. USA)

** High-resolution Karlheiz Hinze S/N151385 endoscope (Germany), Storz endoscope video camera (Germany), Panasonic SR 500 video recorder (Japan)
} 
- Sagittal plane computed tomography (CT) scan (soft tissue window) was done for each patient to assess the VP gap size.

\section{Surgical technique:}

Patients were classified into two random groups according to technique of pharyngeal flap;

Group I: Included 10 patients $(7$ males and 3 females) for whom muscular flap augmentation pharyngoplasty was done. Technique used was that described by Gray S et al $1999{ }^{26}$ Figure 2

The standard pharyngeal flap was planned. The mucosa was raised as a superiorly based flap and then the underlying muscle was incised as superiorly based muscular flap then dissected from prevertebral fascia and the elevated separately. The muscle was rolled onto itself superiorly and tacked to the prevertebral fascia. The mucosa was then returned to its original position to minimize secondary intention healing. A muscular bulge was created at the site of velopharyngeal closure to augment the area and provides the patient with the ability to close the velopharyngeal sphincter. The rolled flap offers a buttress for the free edge of the soft palate to engage in patients with coronal or circular patterns of closure.

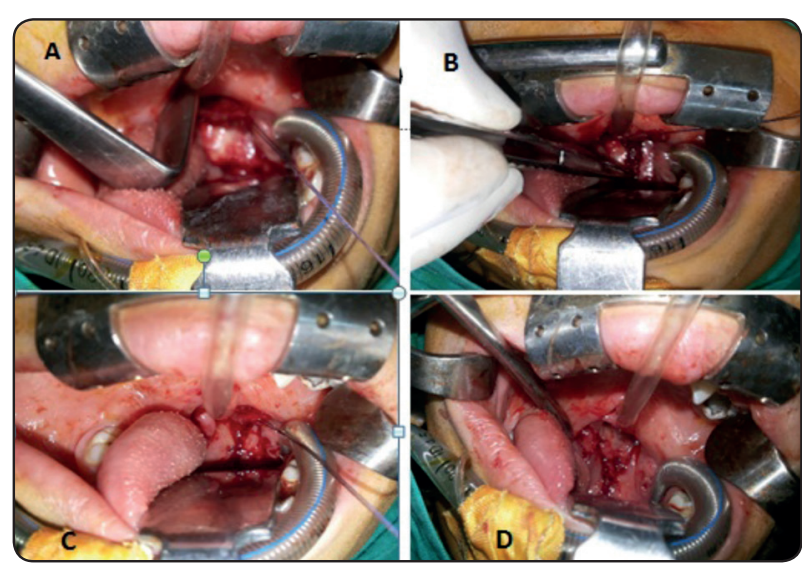

Fig. (2) Surgical technique for muscular flap augmentation of posterior pharyngeal wall $\mathrm{A}$, elevation of muscular flap and exposure of muscle. B. incision through muscle. C. rolling of muscular flap and sutured with prevertebral fascia. D. suturing of mucosal flap in its original position

Group II: Included 10 patients (6males and 4 females) for whom Myomucosal flap augmentation pharyngoplasty was done. Figure 3

- The standard width of a pharyngeal flap generally approximates the distance between the posterior tonsillar pillars. The inferior extent of the flap should be near the midpoint of the tonsil. The length of the flap can be checked by estimating the distance from the posterior pharyngeal wall to the free margin of the soft

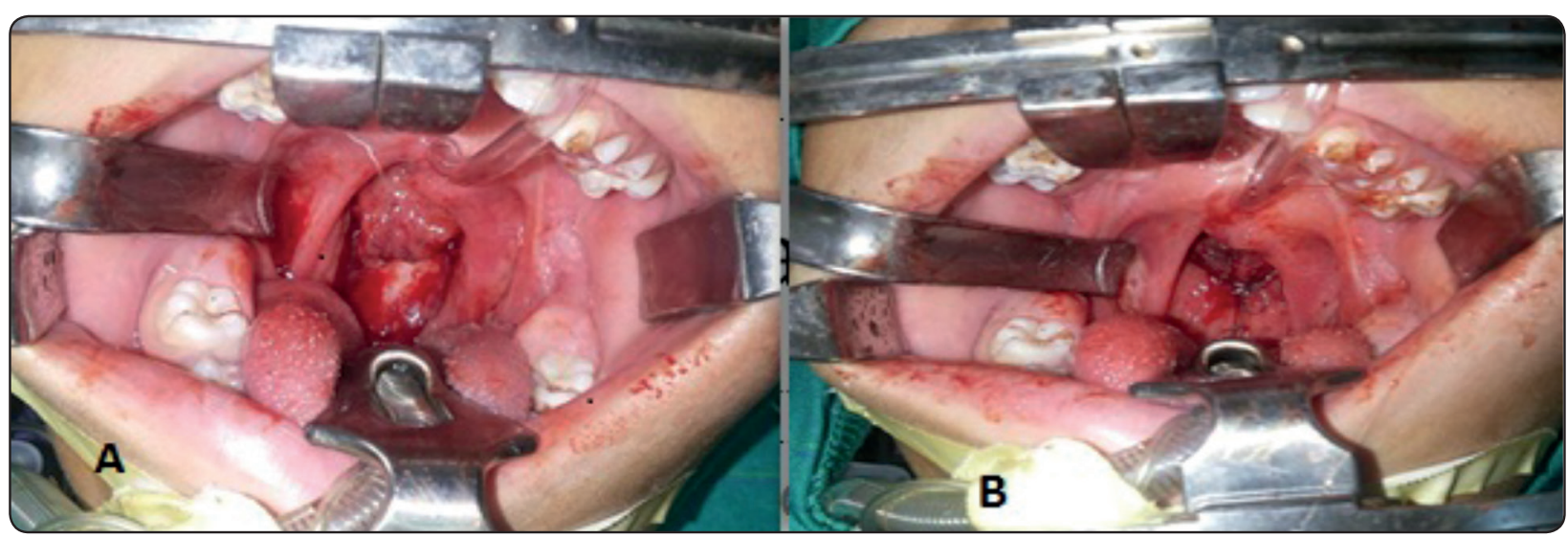

Fig. (3) An intra-operative view showing, A. the superiorly based pharyngeal flap was elevated by incising through mucosa, down to prevertebral fascia (bright white in color). B. Pharyngeal flap was rolled onto itself superiorly and tacked to the prevertebral fascia, the mucosa was primarily closed and muscular bulge was created at the site of velopharyngeal closure. 
palate and then measuring down from the level of velopharyngeal closure

- The superiorly based pharyngeal flap was elevated by incising through mucosa and muscles down to prevertebral fascia. This fascial layer is bright white in color, and the plane will be essentially avascular.

- The superior limbs of this incision were curved slightly laterally near the pedicle of the flap to maximize the blood supply to the flap .Then the mymucosal flap was elevated and rolled onto itself superiorly and tacked to the prevertebral fascia.

The mucosa in both sides were undermined laterally and the defect was then closed primarily with 4-0 vicryl suture

\section{Statistical analysis:}

The collected data was organized, tabulated and statistically analyzed using software statistical computer package version 12 (SPSS). ${ }^{27}$

\section{RESULTS}

This study was conducted on a total number of twenty patients (13 males and 7 females) with velopharyngeal insufficiency. The age of patients was managed ranged from 6.5 to 13 years with mean 8.6.
- Wound healing at the first week postoperative in both groups was repaired by primary intention in both groups. But in group I there is less edema at the surgical site as the mucosal flap was covered the exposed paravertebral fascia without tension

Regarding clinical presentation (hypernasality and nasal regurgitation of fluid) postoperative evaluation revealed that: In group I: six patients revealed improvement of hyper nasality, 4 patients had normal nasal resonance and need for speech therapy In group II: seven patients revealed improvement of hyper nasality, 3 patients had normal nasal resonance and need for speech therapy. All patients in both groups revealed that there is no nasal regurgitation of fluid or food which represents $100 \%$.

- As regard the overall nasalance results (Nasal sentence) measured by nasometry in group I and group II patient: At 9 months noticeable improvement achieved and comparison between both groups through follow up period there was no significance difference for overall nasalance at the final postoperative evaluation period. Table 1.

Regarding the velopharyngeal closure and gap size, preoperative evaluation revealed that, 2 cases was borderline incompetence closure in group I and one case in group II and incompetence closure was in 8 case in group I and 9 cases in group II.

TABLE (1) Shows pre and postoperative the overall nasalance results measured by nasometry in group I and group II patients

\begin{tabular}{|c|c|c|c|c|c|c|}
\hline \multirow{2}{*}{ Follow up period } & \multicolumn{2}{|c|}{ Group(I) } & \multicolumn{2}{c|}{ Group(II) } & \multicolumn{2}{c|}{ Significance test } \\
\cline { 2 - 8 } & Range & Mean \pm S. D & Range & Mean \pm S. D & t. test & p. value \\
\hline Pre-operative & $58.00-79.00$ & $66.908 .17 \pm$ & $58.00-79.00$ & $66.90 \pm 7.48$ & 0.734 & 0.403 \\
\hline One month (post) & $58.00-75.00$ & $65.30 \pm 6.53$ & $58.00-77.00$ & $69.40 \pm 7.14$ & 1.796 & 0.197 \\
\hline 6months (post) & $52.00-65.00$ & $56.90 \pm 4.48$ & $49.00-68.00$ & $54.40 \pm 6.88$ & 0.926 & 0.349 \\
\hline 9months (post) & $49.00-55.00$ & $51.40 \pm 1.90$ & $49.00-58.00$ & $51.70 \pm 3.02$ & 0.071 & 0.793 \\
\hline
\end{tabular}

Normal mean $=\quad$ Nasal sentence 48.5 Significant at 0.05 levels 
At the end of follow up period at 9 month revealed that, competence closure was achieved in 6 patients in group I and 4 patients in group II, borderline competence closure was achieved equally in 3 patients in group I and group II, one case borderline incompetence closure in group II and no cases borderline incompetence closure in group I and incompetence closure was achieved in one case in group I and 2 cases in group II. Figure 4, Table 2

- Sagittal plane computed tomography (CT) scan (soft tissue window) as done for each patient preoperative, immediate and 9 months

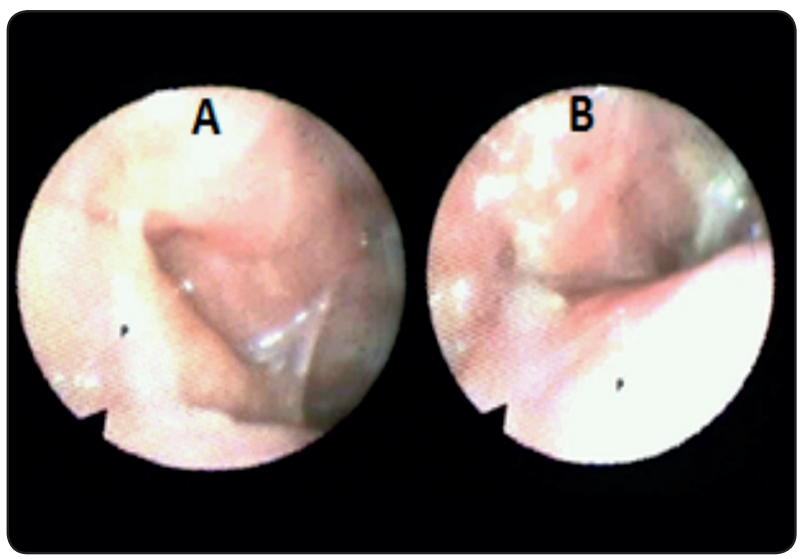

Fig. (4) (A) preoperative nasopharyngoscopic view showing incompetent velopharynx during speaking ( $\mathrm{p}$ : soft palate) (B) 9 month postoperative nasopharyngoscopic view showing competent velopharynx during speaking. postoperative to measure the velophryngeal distance.

- Comparing preoperative and postoperative measures of velopharnygeal distance for each group there is a significant difference as $\mathrm{P}$ value was 0.04 in group I and 0.03 in group II.

- Comparing preoperative and postopearative measures for both groups there was no significant difference regarding reduction of median velopharyngeal distance, $P$. value was 0.706 . Figure 5, tables 3

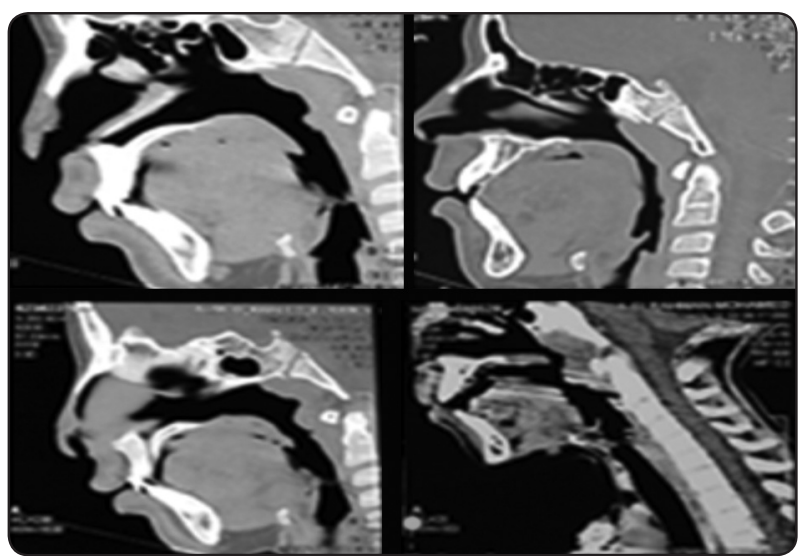

Fig. (5) Preoperative sagittal CT view (Group I left, Group II) (Upper). Nine months postoperative sagittal CT view Group I (left, Group II (right), the muscular bulge was created at good level with soft palate and with reduction in midsagittal distance ( Lower)

Table (2) Show pre and postoperative degree of VP closure using nasopharyngoscopy of group I and group II patients.

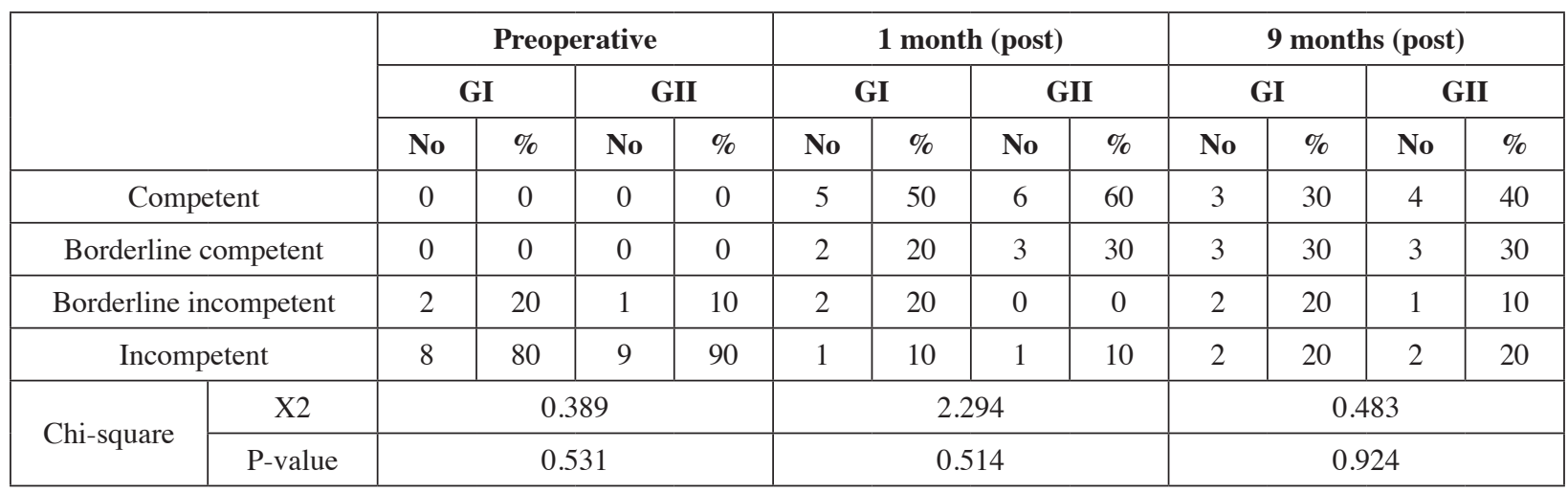

Significant at 0.05 levels 
TABLE (3) Show pre and postoperative range and mean for velophryngeal distance by CT for group I \& II patients

\begin{tabular}{|c|c|c|c|c|c|c|}
\hline \multirow{2}{*}{$\begin{array}{l}\text { Follow up } \\
\text { period }\end{array}$} & \multicolumn{2}{|c|}{$\begin{array}{c}\text { Group (I) } \\
\text { Study }\end{array}$} & \multicolumn{2}{|c|}{$\begin{array}{c}\text { Group (II) } \\
\text { Control }\end{array}$} & \multicolumn{2}{|c|}{ Significance test } \\
\hline & $\begin{array}{c}\text { Range } \\
(\mathrm{mm})\end{array}$ & $\begin{array}{c}\text { Mean } \pm \text { S.D } \\
(\mathrm{mm})\end{array}$ & $\begin{array}{l}\text { Range } \\
(\mathrm{mm})\end{array}$ & $\begin{array}{c}\text { Mean } \pm \text { S. D } \\
(\mathrm{mm})\end{array}$ & t. test & p. value \\
\hline Pre-operative & $5.00-13.00$ & $9.80 \pm 2.49$ & $5-13.00$ & $9.30 \pm 2.26$ & 0.221 & 0.644 \\
\hline Immediate (post) & $4.00-11.00$ & $7.80 \pm 2.20$ & $4.00-11.00$ & $8.20 \pm 2.10$ & 0.173 & 0.682 \\
\hline 9months(post) & $4.00-11.00$ & $7.80 \pm 2.20$ & $4.00-11.00$ & $7.40 \pm 2.46$ & 0.174 & 0.706 \\
\hline $\begin{array}{c}\text { Comparing betwee } \\
\text { pre \& 9m post } \\
\text { P value }\end{array}$ & \multicolumn{2}{|c|}{0.04} & \multicolumn{2}{|c|}{0.03} & & \\
\hline
\end{tabular}

Significant at 0.05 levels

\section{DISCUSSION}

The golden rule in cleft palate surgery is closing the entire palate as long and as functional as possible. It may be possible to see VPI despite all precautions. ${ }^{28-30}$

Timing in the treatment of VPI is very important. Speech development may not allow a definite diagnosis of VPI until the patient is 2 to 3 years or older. Besides the objective diagnostic methods such as nasopharyngoscopy, pressure-flow measurements cannot be applied until the patient is 4 to5 years, that young patients were better candidates for augmentation pharyngoplasty ${ }^{31,32}$

Van Demark and Hardin ${ }^{26}$ showed that articulation therapy in children with cleft palate had slower improvement than expected. So they prefer the closure deficit with surgical measures. The treatment of the VPI is based mostly on pharyngeal flap surgery. Some risks related with pharyngeal flap surgery such as obstructive sleep apnea led the surgeons to look for safer techniques in correcting VPI. Many studies documented the posterior pharyngeal wall augmentation in mild VPI as a safer technique. ${ }^{33-35}$
Posterior pharyngeal wall augmentation was appropriate for patients with minimal velopharyngeal gap; it could be performed with autogenous tissue or foreign implants. The main problem in posterior pharyngeal augmentation technique lies in using the most appropriate material to augment the posterior wall of the pharynx. None autogenous augmentation has not been accepted widely because of the migration or extrusion of alloplastic implants and the resorption of injected materials. Absorption of the autogenous material such as cartilage, fat, and fascia is unavoidable..$^{36-38}$

Rolled pharyngeal flap was considered when significant VPI was associated with longitudinal gap, a muscular bulge was created at the site of velopharyngeal closure to augment the area and provide the patient with the ability to close the velopharyngeal sphincter. ${ }^{26}$

Perceptual assessment is a necessary first step in the evaluation of abnormal speech because treatment is indicated only when a problem is perceived. In fact perceptual assessment is believed to be an important source of information on how well the VP structures function during speech. The nasopharyngoscopy was used to measure VP gap size, and it is widely accepted as the best approach 
for the clinical analysis of the VP sphincter. The subjective nature of auditory perceptual assessement was partially overcome by using the nasometer, which has previously been proved to be satisfactory in this respect. ${ }^{24,39}$

In regarding to the clinical results of this study, the hyper nasal speech was found preoperatively in many of the patients included in this study (100\%), which was attributed primarily to effect of the initial cleft repair producing short palates (velopharyngeal incompetence) and secondarily to the presence of the oronasal fistula. This finding was also demonstrated by Schultes $\mathbf{G},{ }^{40}$ who reported leaking of air into the nose causing speech distortion due to the presence of oronasal fistula, together with the other related symptoms.

Perceptual analysis for patients in this study revealed that, the hypernasality was improved (65\%) for patients of both group. Audible nasal emission was found to be in agreement with Charles F et al, ${ }^{41}$ who showed a trend toward improvement which however did not reach statistical significant and compensatory articulation and overall intelligibility did not change significantly in comparison between both groups.

The intraoperative time was long in group I as the mucosal flap was elevated first then the muscular flap which was taken more time during surgery than in group II in which the flap was elevated as one layer which make it more easier and shorter than group I. As a regard to healing in both groups it was performed by primary healing as the wounds were closed primarily

The mean of overall nasalance for nasal sentences in our study was near to the normal mean $48.5 \%$. However no significant difference was obtained between both group (study and control) Improvement, partial or complete recovery was obtained in $80 \%$ of patients the result may be considered comparable with the outcome achieved by other authors (85-100\%). ${ }^{36}$ The remaining patient did improve but improvement was considered insufficient, the patient continued to suffer from excessive hypernasality .

Regarding the velopharyngeal function and closure pattern as evaluated by nasopharyngoscopy, the coronal pattern was observed in $75 \%$ of patient in our study and only $25 \%$ had circular pattern and this finding was in agreement with Witzel and Posnick ${ }^{42}$. All the patients of both group of our study were having a relatively small but consistent velopharyngeal gap during phonation. Competent and borderline competence closure was achieved in $70 \%$ of patients, $10 \%$ borderline incompetence closure and $20 \%$ of patients had dysfunction which lead of obvious speech problem.

The VP distance measured in CT during vocal rest was reduced 9 months postoperatively. However, there was no significant difference between both groups. This result with parallel with Ulkur et al, ${ }^{14}$ who find that the distance between the posterior pharyngeal wall and the velum observed preoperatively had disappeared in the postoperative follow period.

\section{CONCLUSION}

At the end, we can concluded that

1. The posterior pharyngeal wall augmentation is a good technique for treatment of VPI.

2. As there no significant difference in the results of both groups. The myomucosal flap technique for is simple and easier than the muscular flap technique for posterior pharyngeal wall augmentation.

\section{REFERENCES}

1. Huang MH, Lee ST, Rajendran K. Anatomic basis of cleft palate and velopharyngeal surgery: implications from a fresh cadaveric study. Plast ReconstrSurg. 1998; 101:613-627.

2. Croft C, Shprintzen R, Rakoff S: Patterns of velopharyngeal valving in normal fand cleft palate subjects: A multi-view videofluoroscopic study. Laryngoscope. 1981, 91:265-271. 
3. Henry A. Milczuk, M.D., Dana S. Smith, M.D., Janet H. Brockman, M.S. Surgical Outcomes for Velopharyngeal Insufficiency in Velocardiofacial Syndrome and Nonsyndromic Patients. Cleft Palate-Craniofacial Journal, July 2007, Vol. 44 No. 4

4. Morris HL. Velopharyngeal competence and primary cleft palate surgery, 1960-1971: a critical review. Cleft Palate J. 1973;10:62-71.

5. Shprintzen RJ, Golding-Kushner KJ. Evaluation of velopharyngeal insufficiency. Otolaryngol Clin North Am. 1989;22:519-536

6. Passavant G. Ueber die Beseitigung der naselnden Sprache bei angeborenen Spalten des harten und weichen Gaumens (Gaumensegel- Schlundnacht und Ruccklagerung des Gaumensegels). Arch Klin Chir. 1865;6:333-349. Quoted from Sloan,G :Posterior Pharyngeal Flap and Sphincter Pharyngoplasty: The State of the Art, Cleft Palate-Craniofacial Journal, 37;2;112-122; 2000.

7. Argamaso R.V: The pharyngeal flap. In: Kernahan D., Rosenstein S., eds Cleft palate: A system of management. Boston: Little. Brown, 1990.

8. Crockett DJ, Goudy SL. Update on surgery for velopharyngeal dysfunction. Curr Opin Otolaryngol Head Neck Surg. 2014 Aug. 22(4):267-75.

9. Marsh JL, Grames LM, Holtman B. Intravelar veloplasty: a prospective study. Cleft Palate J. 1989 Jan. 26(1):46-50.

10. D'Antonio LL. Correction of velopharyngeal insufficiency using the Furlow double-opposing Z-plasty. West J Med. 1997 Aug. 167(2):101-2.

11. Sommerlad BC, Mehendale FV, Birch MJ, Sell D, Hattee C, Harland K. Palate re-repair revisited. Cleft Palate Craniofac J. 2002 May. 39(3):295-307.

12. LaRossa $D$. The state of the art in cleft palate surgery. Cleft Palate Craniofac J. 2000 May. 37(3):225-8.

13. Sloan GM. Posterior pharyngeal flap and sphincter pharyngoplasty: the state of the art. Cleft Palate Craniofac J. 2000 Mar. 37(2):112-22.

14. Ulkur E, Karagoz H, Uygur F, et al: The use of porous polyethelen implant for augmentation of the posterior pharynx in young adult patients with borderline velopharyngeal insufficiency. J Craniofac Surg. 2008, 19(3):537.

15. Willging JP. Velopharyngeal insufficiency. Int J Pediatr Otorhinolaryngol. 1999;49(S)1:S307-S309.
16. Pinto JH, Dalben GS, Pegoraro-Krook MI. Speech intelligibility of patients with cleft lip and palate after placement of speech prosthesis. Cleft Palate Craniofac J. 2007;44:635-641

17. Witt PD, Marsh JL, Muntz HR, Marty-Grames L, Watchmaker GP. Acute obstructive sleep apnea as a complication of sphincter pharyngoplasty. Cleft Palate Craniofac J. 1996;33:183-189

18. Kasten SJ, Buchman SR, Stevenson C, Berger M. A retrospective analysis of revision sphincter pharyngoplasty. Ann Plast Surg. 1997;39:583- 589

19. Darryl Lau, B.A., Adam J. Oppenheimer, M.D., Steve R. Buchman, M.D., Mary Berger, M.S., C.C.C., Steven J. Kasten, M.D. Posterior Pharyngeal Fat Grafting for Velopharyngeal Insufficiency; Cleft Palate-Craniofacial Journal, January 2013, Vol. 50 ,51-58

20. Borel-Maisonny: L'insuYsance vélaire, point de vue de l'orthophoniste. Reeduc Orthoph. 1975, 13:61-81.

21. Fletcher SG, Adams LE \& McCutchean MJ: Cleft palate speech assessment through oral-nasal acoustic measures. In Bzoch KR (Ed) Communication Disorders Related to Cleft Lip and Palate. Boston: College-Hill Press. (3rd Ed), 1989, 246-257.

22. Dalston RM and Seaver EJ: Relative values of various standardized passages in nasometric assessment of patients with velopharyngeal impairment. Cleft Palate J.1992, 29:170.

23. Fletcher SG: "Nasalance" vs. listner judgements of nasality. Cleft Palate J.1976, 13:31-44.

24. Derek CY, Lam J \& Jonathan A, et al: Comparison of nasoendoscopy and multiview videofluoroscopy in assessing velopharyngeal insufficiency. Otolaryngol Head Neck Surg.2006, 134:394-402.

25. Perkins JA, Lewis CW, \& Gruss JS, et al: Furlow palatoplasty for management of velopharyngeal insufficiency: A prospective study of 148 consecutive patients. Plast Reconstr Surg.2005, 116:72-80.

26. Gray S, Pinborough-Zimmerman J, Catten M: Posterior wall augmentation for treatment of velopharyngeal insufficiency. Otolaryngol Head Neck Surg 121:107-112, 1999

27. Dawson S and Trapp R: Basic and clinical biostatistic. 2 nd edition. Lange Medical Book, Prentice-Hall International Inc.1994. 
28. Ren YF \& Wang Gh: A modified palatopharyngoplasty flap operation and its application in the correction of velopharyngeal incompetence. Plast Reconstr Surg.1993, 91:612-617.

29. Sirois M, Caouette-Laberge L, Spier S, et al: sleep apnea following a pharyngeal flap: a feared complication. Plast Reconstr Surg. 1994, 93:943-947.

30. Valnicek S, Zuker R, Halpern L, et al: Preoperative complication of superior pharyngeal flap surgery in children. Plast Reconstr Surg.1994, 93: 954-958.

31. Witt PD, Marsh JL, O'Daniel TG, et al: Surgical management of velopharyngeal dysfunction: outcome analysis of autogenous posterior pharyngeal wall augmentation. Plast Reconstr Surg. 99(5): 1997, 1287-1297.

32. Parton MJ \& Jones AS: Hypernasality following adenoidectomy: A significant and avoidable complication. Clin Otolaryngol. 1998, 23(1): 18-19.

33. Trigos I, Gonzalez A, Vazquez MC, et al: Surgical treatement of borderline velopharyngeal insufficiency using homologous cartilage implantation with videonasopharyngoscopic monitoring. Cleft Palate J.1988, 25(2): 167-170.

34. Rubin HJ: Misadventures with injectable Teflon. Arch Otolaryngol. 1975, 101(2):114-116.

35. Ellis JC, De Santo LW, Reiman HV, et al: Migration of Teflon after vocal cord injection. Otolaryngol Head Neck Surg.1987, 96(1):63-66.
36. Chen YH \& Cui HG: High density porous polyethylene material (Medpore) as an unwrapped orbital implant. J Zhejiang Univ Science. 2006, 7(8): 679-682.

37. Abdel-Aziz M: Treatment of submucous cleft palate by pharyngeal flap as a primary procedure. Int J pediatr Otolaryngolo 2007, 71;1083-1097.

38. Wolford LM, Oelschlaeger M, \& Deal R: Proplast as a pharyngeal implant to correct velopharyngeal insufficiency. Cleft Palate J. 1989, 26:119-126.

39. Gamal Youssefa, Anwar Alkhajab: The role of auditory perceptual analysis of speech in predicting velopharyngeal gap size in children with velopharyngeal insufficiency Egypt J Otolaryngol.2015, 31:122-127.

40. Schultes G., Gaggl A. \& Karcher H.: Comparison of periodontal disease in patients with clefts of palate and patients with unilateral clefts of lip, palate, and alveolus. Cleft palate Craniofac. J. 1999,36:322.

41. Charles F, Michael M, Ingegerd A, et al : Autologous fat transplantation to velopharynx for treating persistent velopharyngeal insufficiency of mild degree secondary to overt or submucous cleft palate J Plast Reconstr Aesth Surg. 2013 66,337-344.

42. Witzel MA \& Posnick J: Patterns and location of velopharyngeal valving problems: atypical findings on video nasopharyngoscopy. Cleft Palate J. 1989, 1:63-67. 